\title{
Changing Input-Output Coefficients: The Case of West Virginia
}

\author{
Anthony L. Loviscek*
}

This study analyzes changes in input-output coefficients for the West Virginia economy. The study uses the 1965 and 1975 survey-based West Virginia input-output tables. ${ }^{1}$ First, changes are reported on demand (input) and supply (output) sides, using direct coefficient and Leontief inverse matrices. Second, pictorial representations of input-output change are analyzed using graph-theoretic techniques.

Carter [4] has emphasized the reason for using both direct coefficient and Leontief inverse matrices in analyzing changing input-output structures:

Measures of structural change based on inverse coefficients have some important advantages over direct coefficient comparisons. Steel for refrigerator doors, for example, may be purchased directly from iron and steel in one year and indirectly, through the stampings sector, the next. Measures based on the inverse matrix, however, have their own disadvantages. In particular, they tend to obscure the primary locus of change. ${ }^{2}$

The scope of this paper is not with causes of coefficient change, but with the direction and degree of coefficient change-a necessary first step in analyzing such change. Determining the many causes of coefficient change is beyond the scope of this paper.

\section{PRICE DEFLATION}

Each transactions table reflects producers' prices as follows:

(1) $a_{i j}=q_{i j}\left(\frac{P_{i}}{P_{j}}\right)$,

where

$\mathrm{a}_{\mathrm{ij}}=$ a direct purchase from sector $\mathrm{i}$ by sector $\mathrm{j}$ in value terms,

$\mathrm{q}_{\mathrm{ij}}=\mathrm{a}$ direct purchase from sector $\mathrm{i}$ by sector $\mathrm{j}$ in physical terms, and

$P_{i}, P_{j}=$ output prices for sectors $i$ and $j$.

\footnotetext{
*Assistant professor of business and economics, Indiana University-Purdue University, Fort Wayne. The author thanks William H. Miernyk, Frank Giarratani, and two anonymous referees for comments on an earlier draft. Any errors are the author's responsibility.
} 
Deflating the 1975 table is a necessary first step for analyzing changes in physical coefficients. This is because input and output prices usually move in the same direction after an appropriate lag. Inputs with relatively declining prices may be substituted for those with relatively rising prices, especially when the base years are a decade apart. The use of constant prices shows how substitution has contributed to structural change. ${ }^{3}$

Deflating the 1975 prices was a difficult process. There were qualitative changes in some industries' outputs, although we implicitly assume homogeneity of output. Another problem is raised by possible errors in price deflators. If the 1975 deflator for the chemicals sector-one of West Virginia's major industries - was too small, for example, the output of this industry is overstated when compared with 1965 transactions. The chemical sector's row coefficients would be overstated by a fixed proportion. On the other hand, its column coefficients would be understated by the same fixed proportion. The only consolation is that such distortions, if they exist, affect only the sectors in which the errors occur. Finally, and unfortunately, some differences in the coefficients reflect random factors. Different methods were used to estimate interindustry relationships in the two years, and there are differences in the quality and accuracy of the data in the two sets of tables. ${ }^{4}$

\section{DEMAND SIDE COMPUTATIONS}

Leontief [8] and Carter [4] used inverse matrices for different time periods with vectors of final demand for a given time period to analyze changes in intermediate and gross output levels over time. The same approach was applied to the West Virginia data as follows:

(2) ${ }_{t} a_{i j}={ }_{t} X_{i j} / t X_{j}$,

where

$\mathrm{t}_{\mathrm{ij}}=\mathrm{a}$ direct purchase from sector $\mathrm{i}$ by sector $\mathrm{j}$ in year $\mathrm{t}$ per dollar of $\mathrm{j}$ 's output,

${ }_{\mathrm{t}} \mathrm{x}_{\mathrm{ij}}=\mathrm{a}$ transactions flow from sector $\mathrm{i}$ to sector $\mathrm{j}$ in year $\mathrm{t}$, and

$\mathrm{X}_{\mathrm{j}}=$ gross outlay of sector $\mathrm{j}$ in year $\mathrm{t}$.

The calculations from equation (1) for both years yield the familiar "A" matrices. Multiplying the interindustry coefficients for each year by $1975 \mathrm{sec}-$ toral gross output yields intermediate output $\left(\mathrm{t}_{\mathrm{t}} \mathrm{W}_{\mathrm{i}}\right)$ required from each sector to produce 1975 output with 1965 and 1975 technologies. The results of these calculations are shown in Table 1.

The Leontief inverse matrix is formed in the usual manner from equation (1) to solve for gross output in year $t$ as a function of final use in year $t$, or 
TABLE

(Thousands of dollars)

\begin{tabular}{|c|c|c|c|c|c|c|c|c|}
\hline \multicolumn{4}{|c|}{ Intermediate Outputs } & \multicolumn{5}{|c|}{ Intermediate and Gross Outputs } \\
\hline Sectors & $65^{w_{i}}$ & $75^{w_{i}}$ & \% Change & $75^{\hat{z}_{i}}$ & $4 / c$ Change $^{7 *}$ & $75^{\hat{x}_{i}}$ & $75^{x_{i}}$ & $\begin{array}{c}\% \text { Change } \\
\left(\mathrm{X}_{\mathrm{i}}\right)\end{array}$ \\
\hline 1. Agriculture & 30192 & 30320 & 0.42 & 31197 & -2.81 & 91793 & 90916 & 0.96 \\
\hline 2. Coal min.-under. & 109781 & 72114 & -34.31 & 113415 & -36.42 & 670667 & 629367 & -6.16 \\
\hline 3. Coal min.-strip & 53725 & 48845 & -9.08 & 56433 & -13.45 & 104134 & 96547 & -7.29 \\
\hline 4. Petroleum \& natur. gas & 32319 & 25209 & -22.00 & 31859 & -20.87 & 49042 & 42393 & -13.56 \\
\hline 5. All other mining & 44039 & 40301 & -8.49 & 45324 & -11.08 & 75843 & 70820 & -6.62 \\
\hline 6. Gen. contr.-bldg. & 44622 & 18469 & -58.6 & 43875 & -57.90 & 147905 & 122499 & -17.18 \\
\hline 7. Gen. contr--nonbldg. & 31312 & 26300 & -16.0 & 32209 & -18.34 & 191734 & 185826 & -3.08 \\
\hline 8. Spec. trade contr's & 76519 & 67295 & -12.1 & 83888 & -19.78 & 143640 & 127047 & -11.55 \\
\hline 9. Food-meats & 18708 & 13724 & -26.6 & 19054 & -27.97 & 57732 & 52402 & -9.23 \\
\hline 10. Food-dairies & 6370 & 6015 & -5.6 & 6323 & -4.86 & 34479 & 34172 & -0.89 \\
\hline 11. Food-bakeries & 4632 & 5553 & 19.9 & 4594 & 20.89 & 44300 & 45260 & 2.17 \\
\hline 12. Food-bev's & 2282 & 4466 & 95.75 & 2227 & 100.55 & 33647 & 35886 & 6.66 \\
\hline 13. Apparel & 1581 & 1756 & 11.09 & 1560 & 12.61 & 49803 & 50000 & 0.40 \\
\hline 14. Log \& sawmills & 19726 & 24552 & 24.97 & 19985 & 22.85 & 37408 & 41975 & 12.21 \\
\hline 15. Furniture & 5741 & 3009 & -47.59 & 6082 & -50.52 & 43011 & 39938 & -7.14 \\
\hline 16. Print. \& publish. & 61594 & 61592 & $-0-$ & 60203 & 2.31 & 84715 & 86106 & 1.64 \\
\hline 17. Chemicals & 214629 & 176568 & -17.73 & 221912 & -20.43 & 1328850 & 1283506 & -3.41 \\
\hline 18. Petroleum & 44721 & 33978 & -24.02 & 46154 & -26.38 & 71070 & 58894 & -17.13 \\
\hline 19. Glass & 11703 & 14031 & 19.89 & 11529 & 21.71 & 208705 & 211208 & 1.20 \\
\hline 20. Stone \& clay & 34230 & 52018 & 51.97 & 36908 & 40.94 & 139708 & 154818 & 10.82 \\
\hline 21. Primary metals & 77668 & 66007 & -15.01 & 76138 & -13.31 & 832161 & 822031 & -1.23 \\
\hline 22. Fabric. metals & 35841 & 46403 & 29.47 & 37933 & 22.33 & 182831 & 191302 & 4.63 \\
\hline 23. Machinery & 7883 & 12432 & 57.71 & 8215 & 51.33 & 118977 & 123194 & 3.54 \\
\hline 24. Elect. mach. & 4615 & 11778 & 155.21 & 4632 & 154.30 & 156840 & 163987 & 4.56 \\
\hline 25. Transp. equipm. & 2446 & 3812 & 55.86 & 2603 & 46.44 & 130994 & 132202 & 0.92 \\
\hline
\end{tabular}




\begin{tabular}{|c|c|c|c|c|c|c|c|c|}
\hline 26. Instruments & 4054 & 6347 & 56.54 & 4161 & 52.53 & 44803 & 46989 & 4.88 \\
\hline 27. All other manf. & 40015 & 43142 & 7.81 & 40865 & 5.57 & 168918 & 171195 & 1.35 \\
\hline 28. Eat. \& drink. est. & 5010 & 5338 & 6.56 & 4933 & 8.23 & 128928 & 129334 & 0.31 \\
\hline 29. Wholesale trade & 104870 & 115491 & 10.13 & 104987 & 10.01 & 304407 & 314911 & 3.45 \\
\hline 30. Retail food & 1153 & 4574 & 296.84 & 1148 & 298.51 & 195551 & 198978 & 1.75 \\
\hline 31. Retail gas stat's & 9793 & 8946 & -8.65 & 9584 & -6.67 & 54853 & 54214 & -1.16 \\
\hline 32. All other retail & 31571 & 51244 & 62.32 & 31433 & 63.03 & 503594 & 523405 & 3.93 \\
\hline 33. Banking & 30227 & 33103 & 9.52 & 30163 & 97.47 & 113752 & 116692 & 2.59 \\
\hline 34. Other finance & 6074 & 8079 & 33.01 & 6045 & 33.65 & 81680 & 83714 & 2.49 \\
\hline 35. Insurance & 77536 & 79401 & 2.40 & 77234 & 2.81 & 224856 & 227024 & 0.96 \\
\hline 36. Real estate & 41550 & 47908 & 15.30 & 40623 & 17.93 & 118754 & 126039 & 6.13 \\
\hline 37. All other FIRE & 28736 & 27680 & -3.68 & 28532 & -2.99 & 54124 & 53272 & -1.57 \\
\hline 38. Hotels & 5162 & 4250 & -17.66 & 5093 & -16.54 & 45420 & 44578 & -1.85 \\
\hline 39. Medical \& legal & 47157 & 52956 & 12.30 & 47547 & 11.38 & 288335 & 293743 & 1.88 \\
\hline 40. Educat. serv. & 1964 & 17347 & 783.11 & 1927 & 800.42 & 405505 & 420926 & 3.80 \\
\hline 41. All other serv. & 129195 & 158410 & 22.61 & 127903 & 23.85 & 481064 & 511570 & 6.34 \\
\hline 42. Railroads & 64492 & 41423 & -35.77 & 65380 & -36.64 & 338973 & 315016 & -7.07 \\
\hline 43. Truck. \& wareh. & 68020 & 85072 & 25.07 & 67990 & 25.12 & 224848 & 241930 & 7.60 \\
\hline 44. All other transp. & 31841 & 38837 & 21.97 & 31022 & 25.19 & 73842 & 81658 & 10.58 \\
\hline 45. Communications & 52165 & 73229 & 40.38 & 52050 & 40.69 & 166741 & 187920 & 12.70 \\
\hline 46. Elect. companies & 111134 & 101917 & -8.29 & 112232 & -9.19 & 434551 & 424237 & -2.37 \\
\hline 47. Gas companies & 63428 & 78724 & 24.12 & 62897 & 25.16 & 120640 & 136467 & 13.12 \\
\hline 48. Water \& sanitary & 15984 & 12387 & -22.50 & 16846 & -26.47 & 31600 & 27141 & -14.11 \\
\hline Total & $1,948,010$ & $1,962,343$ & $0.74 \%$ & $1,905,347$ & $2.99 \%$ & $9,635,728$ & $9,665,224$ & $0.31 \%$ \\
\hline
\end{tabular}

*between ${ }_{75} \hat{\mathrm{Z}}_{\mathrm{i}}$ and ${ }_{75} \mathrm{~W}_{\mathrm{i}}$ 
(3) ${ }_{t} X_{i}=\Sigma_{j}{ }_{t} Q_{i j}^{-1}{ }_{t} Y_{i}$,

where

${ }_{\mathrm{t}} \mathrm{Q}_{\mathrm{ij}}^{-1}=$ the Leontief inverse showing direct and indirect purchases from sector $\mathrm{i}$ by sector $\mathrm{j}$ in year $\mathrm{t}$ per dollar of delivery to final demand by sector $\mathrm{j}$, and

${ }_{\mathrm{t}} \mathrm{Y}_{\mathrm{i}}=$ final demand for sector $\mathrm{i}$ in year $\mathrm{t}$.

Finding the amount of inputs necessary for satisfying final demand for 1975 using 1965 technology requires the following:

(4) ${ }_{75} \hat{\mathrm{X}}_{\mathrm{i}}=\Sigma_{\mathrm{j}}{ }_{65} \mathrm{Q}_{\mathrm{ij}}^{-1}{ }_{75} \mathrm{Y}_{\mathrm{i}}$

Using 1975 technology in equation (3) requires use of the 1975 Leontief inverse $\left({ }_{75} \mathrm{Q}_{\mathrm{ij}}^{-1}{ }_{75} \mathrm{Y}_{\mathrm{i}}\right)$.

Intermediate output levels for both years are determined as follows:

(5) ${ }_{75} \mathrm{Z}_{\mathrm{i}}=\mathrm{\Sigma}_{\mathrm{j}}{ }_{75} \mathrm{Q}_{\mathrm{ij}}{ }^{-1}{ }_{75} \mathrm{Y}_{\mathrm{i}}-{ }_{75} \mathrm{Y}_{\mathrm{i}}$, and

(6) ${ }_{75} \hat{\mathrm{Z}}_{\mathrm{i}}=\Sigma_{\mathrm{j} 65} \mathrm{Q}_{\mathrm{ij}}^{-1}{ }_{75} \mathrm{Y}_{\mathrm{i}}-{ }_{75} \mathrm{Y}_{\mathrm{i}}$,

where

${ }_{75} \mathrm{Z}_{\mathrm{i}}=$ intermediate output for industry i for 1975

The results of the above computations are shown in Table 1.

\section{SUPPLY SIDE COMPUTATIONS}

Conventional input-output analysis, like much of economics, has underemphasized the supply side. Giarratani [6], however, has emphasized, "the input-output table is a neutral image of an economy, emphasizing neither supply nor demand forces but rather recording equilibrium values at one point in time.".

To get an accurate picture, therefore, of changing interindustry relationships, an examination is also needed of changes in output coefficients. Production relationships underlying these coefficients are determined by the availability of inputs rather than by technical factors. The coefficients are determined as follows:

(7) $\overrightarrow{\mathrm{a}}_{\mathrm{ij}}={ }_{\mathrm{t}} \mathrm{x}_{\mathrm{ij}} / \mathrm{t} \mathrm{X}_{\mathrm{i}}$, 
where

$\overrightarrow{\mathrm{t}}_{\mathrm{i} j}=$ the direct sales of sector $\mathrm{i}$ to sector $\mathrm{j}$ in time period to per unit of sector i's output.

Gross outlay (=output) in year $\mathrm{t}$ is solved for as a function of primary inputs as follows:

(8) $\overrightarrow{\mathrm{X}}_{\mathrm{j}}=\Sigma_{\mathrm{i} \text { t }} \mathrm{V}_{\mathrm{j}} \mathrm{Q}_{\mathrm{ij}}^{-1}$

where

${ }_{\mathrm{t}} \mathrm{V}_{\mathrm{j}}$ is a purchase of primary inputs by sector $\mathrm{j}$ in year $\mathrm{t}$.

The years 1965 and 1975 are substituted for $t$ in equations (6) and (7) in the same manner as in the demand side computations. Intermediate inputs determined from equation (6) are given in Table 2 . Intermediate inputs ${ }_{75} \vec{Z}_{j}$ and ${ }_{75} \overrightarrow{\mathrm{W}}_{\mathrm{j}}$ )-given in Table 2 with gross outlays-are determined by subtracting value added $\left(\mathrm{V}_{\mathrm{j}}\right)$ from gross outlay $\left(\mathrm{X}_{\mathrm{j}}\right)$ in equation $(7)$ for both years.

\section{RESULTS}

Table 1 shows that the percent change in total intermediate requirements between the two years is only $0.74 \%$. Some sectors, however, show considerably greater changes. The sector displaying the largest change is educational services (40) at $783.11 \%$. This reflects the emphasis placed on upgrading West Virginia's educational facilities and programs. The metal-manufacturing bloc underwent significant change as shown by electrical machinery and apparatus (24), machinery-except electrical (23), transportation equipment (25), and instruments and related products (26) at $155.21 \%, 57.71 \%, 55.86 \%$, and $56.54 \%$.

Percent increases in intermediate requirements may appear paradoxical. One usually expects that technological change should lead to less, not more, inputs required to produce the same levels of output at a later date. An increased supply of inputs, however, could result from import substitution. Such increases could also result from an increase in the degree of specialization. Sectors using 1975 technologies may have used more intermediate inputs but less capital and labor than they did in 1965. Nonetheless, substantiation of the reasons for the increases requires thorough analysis of sectoral production functions.

Some sectors show significant decreases. General contractors-building (6) has the largest at $-58.61 \%$. Railroads (42) shows a decline of $35.77 \%$. Finally, coal mining-underground (2) and petroleum (18) changed by $-34.31 \%$ and $-24.02 \%$. This might be due to sectors substituting away from coal and petroleum usage because of rising energy prices. 
(Thousands of dollars)

\begin{tabular}{|c|c|c|c|c|c|c|c|c|}
\hline \multicolumn{4}{|c|}{ Intermediate Outlays } & \multicolumn{5}{|c|}{ Intermediate and Gross Outlays } \\
\hline Sectors & $65^{\vec{w}_{j}}$ & $75^{\vec{w}_{j}}$ & $\%$ Change & $7 \hat{\vec{z}}_{\mathrm{j}}$ & $\%$ Change* & ${ }_{75} \hat{\vec{x}}_{j}$ & ${ }_{75} \vec{x}_{j}$ & $\begin{array}{c}\left.\overrightarrow{\mathrm{X}}_{\mathrm{j}}\right) \\
\text { che }\end{array}$ \\
\hline 1. Agriculture & 34205 & 34198 & -0 & 33547 & 1.94 & 90265 & 90916 & 0.72 \\
\hline 2. Cola min.-under. & 105921 & 146416 & 38.23 & 97054 & 50.86 & 580005 & 629366 & 8.51 \\
\hline 3. Coal min.-strip & 37000 & 74694 & 101.89 & 24863 & 200.42 & 46715 & 96546 & 106.67 \\
\hline 4. Petroleum \& natur. gas & 13953 & 16444 & 17.86 & 13088 & 25.64 & 39037 & 42393 & 8.60 \\
\hline 5. All other mining & 11785 & 14152 & 20.08 & 11621 & 21.78 & 68289 & 70820 & 3.71 \\
\hline 6. Gen. Contr--bldg. & 116044 & 69139 & 40.42 & 115666 & -40.23 & 169026 & 122499 & -27.53 \\
\hline 7. Gen. contr.-nonbldg. & 84587 & 77735 & -8.10 & 80529 & -3.47 & 188620 & 185826 & -1.48 \\
\hline 8. Spec. trade contr's & 38892 & 39776 & 2.27 & 37976 & 4.74 & 125246 & 127046 & 1.44 \\
\hline 9. Food-meats & 19032 & 18786 & -1.29 & 18861 & -0.40 & 52477 & 52402 & -0.14 \\
\hline 10. Food-dairies & 21613 & 11893 & -44.98 & 21553 & -44.82 & 43833 & 34172 & -22.04 \\
\hline 11. Food-bakeries & 10138 & 9340 & -7.88 & 10070 & -7.25 & 45989 & 45260 & -1.59 \\
\hline 12. Food-bev's & 4445 & 5126 & 15.31 & 4460 & 14.93 & 35220 & 35886 & 1.89 \\
\hline 13. Apparel & 2023 & 4603 & 127.56 & 1989 & 131.36 & 47387 & 50000 & 5.52 \\
\hline 14. Log \& sawmills & 18547 & 17039 & -8.13 & 18669 & -8.73 & 43606 & 41976 & -3.74 \\
\hline 15. Furniture & 5701 & 7135 & 25.16 & 5741 & 24.29 & 38544 & 39938 & 3.62 \\
\hline 16. Print \& publish. & 31193 & 33290 & 6.72 & 30206 & 10.21 & 83021 & 86105 & 3.72 \\
\hline 17. Chemicals & 401414 & 281642 & -29.84 & 421421 & -33.17 & 1423285 & 1283506 & -9.82 \\
\hline 18. Petroleum & 24096 & 33495 & 39.10 & 23448 & 42.85 & 48847 & 58894 & 20.57 \\
\hline 19. Glass & 55176 & 40756 & -26.13 & 55598 & -26.70 & 226050 & 211207 & -6.57 \\
\hline 20. Stone \& clay & 36918 & 43505 & 17.84 & 35831 & 21.42 & 147144 & 154817 & 5.22 \\
\hline 21. Primary metals & 117729 & 65609 & -44.27 & 116143 & -43.51 & 872565 & 822030 & -5.79 \\
\hline 22. Fabric. metals & 20474 & 32951 & 60.94 & 20973 & 57.11 & 179324 & 191302 & 6.68 \\
\hline 23. Machinery & 21086 & 15435 & -26.80 & 21225 & -27.28 & 128984 & 123194 & -4.49 \\
\hline 24. Elect mach. & 42164 & 34135 & -19.04 & 43177 & -20.94 & 173028 & 163986 & -5.23 \\
\hline 25. Transp. equipm. & 25790 & 15728 & -39.02 & 26504 & -40.66 & 142979 & 132202 & -7.54 \\
\hline
\end{tabular}




\begin{tabular}{|c|c|c|c|c|c|c|c|c|}
\hline 26. Instruments & 780 & 1381 & 77.13 & 821 & 68.34 & 46428 & 46989 & 1.21 \\
\hline 27. All other manf. & 20577 & 20309 & -1.30 & 20026 & 1.41 & 170913 & 171195 & 0.17 \\
\hline 28. Eat. \& drink. est. & 25341 & 35784 & 41.21 & 25952 & 37.89 & 119502 & 129334 & 8.23 \\
\hline 29. Wholesale trade & 57223 & 41199 & -28.00 & 56581 & -27.19 & 330293 & 314910 & -4.66 \\
\hline 30. Retail food & 39798 & 49814 & 25.17 & 37533 & 32.72 & 186697 & 198978 & 6.59 \\
\hline 31. Retail gas stat's & 10778 & 12605 & 16.95 & 10352 & 21.76 & 51961 & 54214 & 4.34 \\
\hline 32. All other retail & 102059 & 101406 & -0.64 & 98019 & 3.46 & 520018 & 523405 & 0.65 \\
\hline 33. Banking & 12049 & 18946 & 57.24 & 11850 & 59.88 & 109596 & 116692 & 6.47 \\
\hline 34. Other finance & 10100 & 21135 & 109.27 & 9587 & 120.47 & 72165 & 83714 & 16.00 \\
\hline 35. Insurance & 32502 & 15791 & -20.65 & 36294 & -28.94 & 237525 & 227023 & -4.42 \\
\hline 36. Real estate & 20828 & 37723 & 81.12 & 20787 & 81.48 & 109102 & 126039 & 15.52 \\
\hline 37. All other FIRE & 37817 & 27102 & -28.33 & 35679 & -24.04 & 61849 & 53273 & -13.87 \\
\hline 38. Hotels & 20586 & 16270 & -20.96 & 19373 & -16.02 & 47681 & 44578 & -6.51 \\
\hline 39. Medical \& legal & 38422 & 51289 & 33.49 & 37740 & 35.90 & 280195 & 293743 & 4.84 \\
\hline 40. Educat serv. & 44803 & 80247 & 79.11 & 48754 & 64.59 & 389434 & 420926 & 8.09 \\
\hline 41. All other serv. & 6.3823 & 84832 & 32.92 & 63172 & 34.29 & 489909 & 511569 & 4.42 \\
\hline 42. Railroads & 34531 & 22534 & -34.74 & 34879 & -35.40 & 327362 & 315017 & -3.77 \\
\hline 43. Truck. \& wareh. & 25370 & 31102 & 22.59 & 25788 & 20.61 & 236616 & 241930 & 2.25 \\
\hline 44. All other transp. & 14197 & 15143 & 6.66 & 13817 & 9.60 & 80332 & 81658 & 1.65 \\
\hline 45. Communications & 13762 & 16391 & 19.10 & 13654 & 20.05 & 185182 & 187919 & 1.48 \\
\hline 46. Elect. companies & 78111 & 83894 & 7.40 & 67734 & 23.86 & 408076 & 424236 & 3.96 \\
\hline 47. Gas companies & 46898 & 14840 & -68.36 & 44339 & -66.53 & 165966 & 136467 & -1.78 \\
\hline 48. Water \& sanitary & 12919 & 9600 & -25.69 & 12852 & -25.30 & 30393 & 27141 & -10.70 \\
\hline Total & $2,063,200$ & $1,962,359$ & $-4.89 \%$ & $2,022,142$ & $-2.96 \%$ & $9,696,681$ & $9,623,239$ & -0.76 \\
\hline
\end{tabular}

*between ${ }_{75} \hat{Z}_{i}$ and ${ }_{75} \vec{W}_{i}$ 
The other results in Table 1 were derived from Leontief inverses. The changes for total intermediate and gross outputs are $2.99 \%$ and $0.31 \%$, not much different than those in Table 1. Percent changes in intermediate flows calculated from the inverse are generally greater than those calculated from the "A" matrix because of the addition of indirect effects picked up by the inverse. Notable exceptions to this, by as much as $11 \%$, are stone and clay products (20), fabricated metal products (22), machinery-except electrical (23), transportation equipment (25), and instruments and related products (26). The percent decreases mean that secondary output requirements (indirect effects) needed to satisfy final demand requirements have partially offset primary output requirements (direct effects).

Percent changes in gross outputs are relatively small. General contractorsbuilding (6) and petroleum and natural gas (4) have the largest changes. Visual observation shows that intermediate outputs have changed considerably more than gross outputs. This suggests that the regional interindustry structure may be relatively unstable due to import shifts, while the underlying technical relations may be relatively stable. ${ }^{6}$ Testing this assertion, however, requires additional information on import shares and production relationships.

Table 2 shows supply side results. The change for total intermediate requirements is $-4.89 \%$. Energy sectors (2, 3, 4, and 18), however, display much more change than this. For example, coal mining-strip and auger (3) shows an increase of over $100 \%$. Its demand side change, however, is $-9.08 \%$, and is in the opposite direction. This implies that this sector's production function has not changed nearly as much as has its output distribution.

The above sectors show negative percent changes on the demand side, but positive percent changes on the supply side. Some manufacturing sectors $(23$, 24, and 25), however, show the opposite. On the demand side, this might be due to import substitution. On the supply side, it might be due to technological change or to shifts in output distribution from intermediate stages to final demand. Regardless, substantiation of such causes depends on full information about production functions and sectoral output distribution.

Changes for intermediate and gross output sums are $-2.96 \%$ and $0.76 \%$, not much different from those in Table 3. This suggests that indirect effects had a relatively small impact on structural change. The exception to this is coal mining - strip and auger (3), showing a percent jump of almost $100 \%$.

There are few large percent changes in gross outputs. Once again, coal mining-strip and auger (3) displays the greatest change, followed by general contractors-building (6), food and kindred products-dairies (10), and petroleum (18). As in the demand side results, greater change is shown in intermediate inputs than is shown in total outlays. This suggests that regional interindustry relationships might be unstable compared to technical relationships. 
TABLE 3

Clusters

\section{5}

1. Petroleum \& natural gas (4)

Gas companies \& systems (47)

$$
\mathrm{L}=0.39
$$

2. Chemicals (17)

Instruments \& related products (26)

$$
\mathrm{L}=0.19
$$

3. General contractors-nonbuilding (7)

Petroleum (18)

$$
\mathrm{L}=0.23
$$

4. General contractors-building (6)

Special trade contractors (8)

$$
\mathrm{L}=0.29
$$

5. Logging \& sawmills (14)

Furniture \& other wood fabrication (15)

$$
\mathrm{L}=0.09
$$

6. Insurance agents \& brokers (35)

All other FIRE (37)

Medical \& legal services (39)

$$
\mathrm{L}=0.28(35,37) ; \mathrm{L}=0.27(37,39)
$$

7. Agriculture (1)

Food \& kindred products--meats (9)

Food \& kindred products-dairies (10)

$$
\mathrm{L}=0.14(1,9) ; \mathrm{L}=0.18(1,10)
$$

1975

1. All other FIRE (37)

Medical \& legal services (39)

Insurance agents (35)

$\mathrm{L}=0.17(35,37) ; \mathrm{L}=0.26(37,39)$

2. General contractors-building (6)

Special trade contractors $(8)$

$\mathrm{L}=0.21$

3. Petroleum \& natural gas (4)

Gas companies \& systems (47)

$$
\mathrm{L}=0.14
$$

4. General contractors-nonbuilding (7)

Petroleum (18)

All other mining (5)

$\mathrm{L}=0.21(7,18) ; \mathrm{L}=0.12(5,18)$

5. Agriculture (1)

Food \& kindred products-dairies (10)

Food \& kindred products-meats (9)

$\mathrm{L}=0.13(1,9) ; \mathrm{L}=0.15(1,10)$

6. Coal mining-underground (2)

Logging \& sawmills (14)

Coal mining-strip (3)

Furniture \& wood fabrication (15)

$\mathrm{L}=0.14(2,14) ; \mathrm{L}=0.12(2,3)$;

$\mathrm{L}=0.09(14,15)$

\section{APPLICATION OF GRAPH THEORY}

As applied to input-output analysis, graph theory represents an application of cluster analysis. Cluster analysis is a tool of scientific inquiry used for making inductive generalizations-that is, bringing order to data. Yet it can be used in a deductive sense. For instance, the Hirschman linkage hypothesis suggests that sectors with the strongest interindustry linkages have dominant influence on growth and decline. ${ }^{8}$ If true, this means that identification of such sectors and those linked to them are important for regional and urban policy. Identifying such sectors might be accomplished easily and efficiently by applying a graph-theoretic clustering algorithm to input-output data.

Campbell [3] has recommended the application of graph theory to inputoutput tables for identifying sectors for growth pole strategy. Siebert [12] has suggested using graph theory for representing the interdependence of spatial points to determine regional centers of economic activity. Slater [13] has used graph theory to expose salient and subtle structural features of input-output flows. 
The approach used here is a variant of that used by Slater. ${ }^{9}$ It generates a hierarchical representation of an economy's set of interindustry linkages at a given point in time. The hierarchical representation is provided pictorially by a dendrogram-a diagram showing how sectors are linked by the range of values of the interindustry linkages. Changes over time in interindustry relationships will change the dendrogram's hierarchical representation.

The dendrograms for 1965 and 1975 were generated from a matrix (B) of backward and forward linkages calculated as follows:

(9) $\mathrm{t}_{\mathrm{i}} \mathrm{b}_{\mathrm{ij}}=0.5\left(\mathrm{a}_{\mathrm{t}}+{ }_{\mathrm{t}} \mathrm{a}_{\mathrm{ij}}\right)$,

where

${ }_{\mathrm{t}} \mathrm{a}_{\mathrm{ij}}=\mathrm{a}$ direct input coefficient defined in equation (1), and

$\vec{t}_{\mathrm{ij}}=$ a direct output coefficient defined in equation (6).

To construct a dendrogram, each West Virginia sector is represented by a vertex without any linkages between sectors. The largest linkage is found, and an arrow is drawn between the corresponding sectors. This procedure is followed sequentially for the second, third, and nth largest linkage until all sectors are linked. Any two sectors are considered linked as long as a linkage exists between sector $\mathrm{i}$ and sector $\mathrm{j}$, without regarding which sector is purchasing from the other. ${ }^{10}$

Unfortunately, an adequate statistical procedure for determing clusters from dendrograms does not exist at present. An analyst, therefore, must visually scan the dendrogram to determine clusters. This is accomplished by using the threshold scale at the top of the dendrogram. ${ }^{11}$ Two sectors are said to be joined if the linkage joining them exceeds a threshold level (read from right to left at the top of a dendrogram). For example, if the threshold is set at 27 in Figure 1, only three clusters exist: petroleum and natural gas (4) and gas companies and systems (47); general contractors-building (6) and special trade contractors (8); and insurance (35), "all other" FIRE (37), and medical and legal services (39). As the threshold is lowered to 14 , however, other clusters [e.g., chemicals (17) and instruments and related products (26)] appear. Finally, when the threshold is lowered to approximately 2 , all 48 sectors are linked hierarchically. Those clusters that exist at a relatively high threshold can be said to be salient because the linkages joining the sectors comprising the clusters are the strongest in the economy. In some cases, salient clusters "can be regarded as relatively integrated self-propulsive groups of industries. Increases in the production of one member industry will place added demands on every other constituent." 1.2

Visual examination of Figure 1 suggests that seven clusters exist; while that of Figure 2 suggests that six exist. These clusters are represented in Table 3 with a linkage index (L) representing the degree of strength of the linkages 
FIGURE 1

Dendrogram, 1965

$\begin{array}{llll}39 & 27 & 14 & 2\end{array}$

4. Crude petr.\&nat. gas

47. Gas companies

17. Chemicals

26. Instruments

7. Gen.contr.-nonbldg.

18. Petroleum

6. Gen. contr.-bldg.

8. Spec. trade cont's

48. Water\&sanitary

20. Stone\&clay

5. All other min.

40. Educat. serv.

22. Fabric. metals

21. Primary metals

24. Elect. machinery

44. All other transp.

16. Print.\&publish.

32. All other retail

36. Real estate

30. Retail food

19. Glass

27. All other manf.

25. Transp. equipm. 42. Railroads

31. Retail gas stat's

41. All other serv.

29. Wholesale trade

43. Truck.\&wareh.

38. Hotels

14. Log.\&sawmills 15. Furniture

3. Coal min.-under. 46. Elect. companies

2. Coal min.-strip 35. Insurance

37. All other FIRE

39. Medical\&legal 1. Agriculture

10. Food-dairies

9. Food-meats

28. Eat.\&drink, est.

11. Food-bakeries

45. Communications

23. Machinery

33. Banking

34. Other finance 13. Apparel

12. Food-bev's

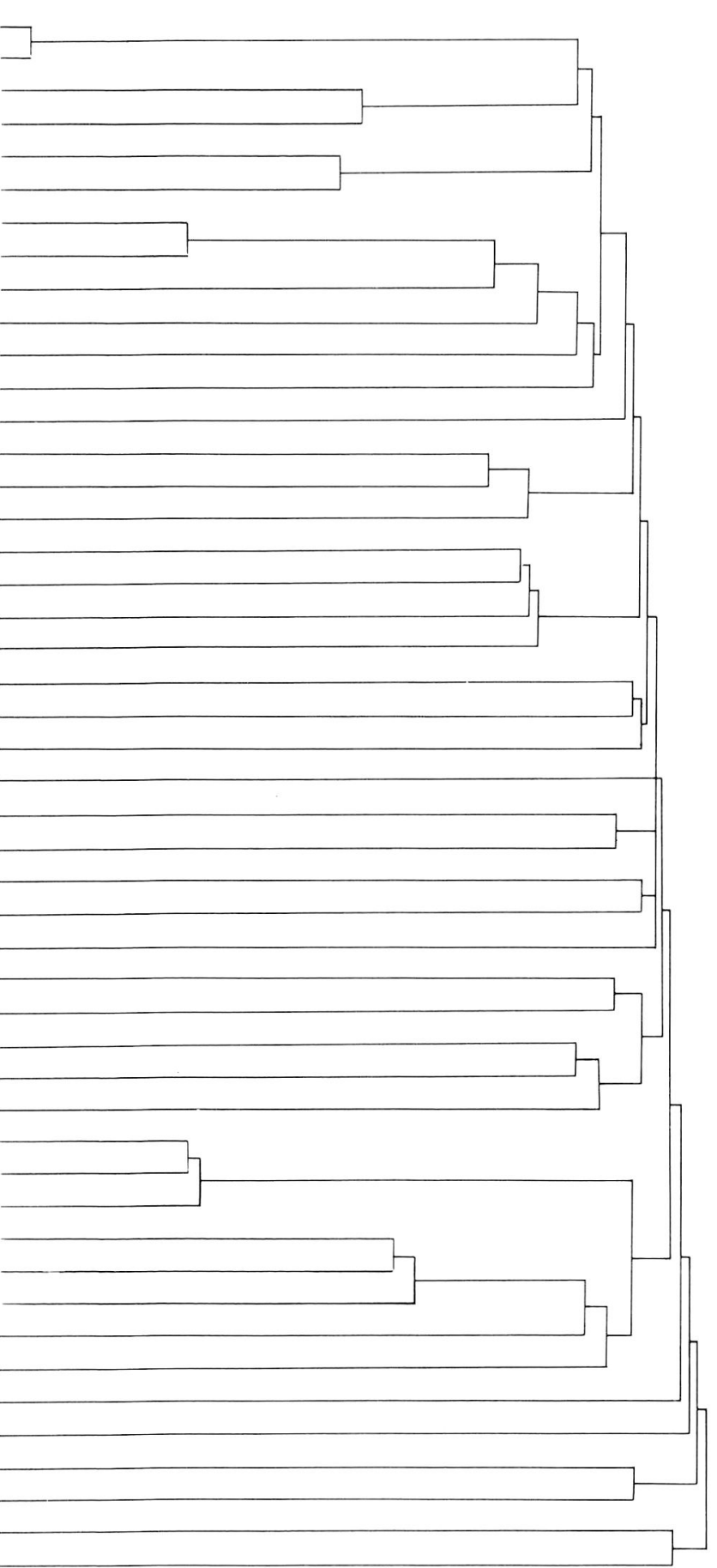


FIGURE 2

Dendrogram, 1975

37. All other FIRE

39. Medical\&legal 35. Insurance

6. Gen. contr.-bldg.

8. Spec. trade cont's 20. Stone\&clay

4. Crude petr.\&nat. gas 47. Gas companies

7. Gen. contr.-nonbldg.

18. Petroleum

5. All other min.

17. Chemicals

48. Water\&sanitary

22. Fabric. metals

21. Primary metals

24. Elect. machinery

26. Instruments

30. Retail food

36. Real estate

16. Print.\&publish.

32. All other retail

41. All other serv. 33. Banking

34. Other finance 44. All other transp.

$\begin{array}{llll}26 & 18 & 10 & 2\end{array}$

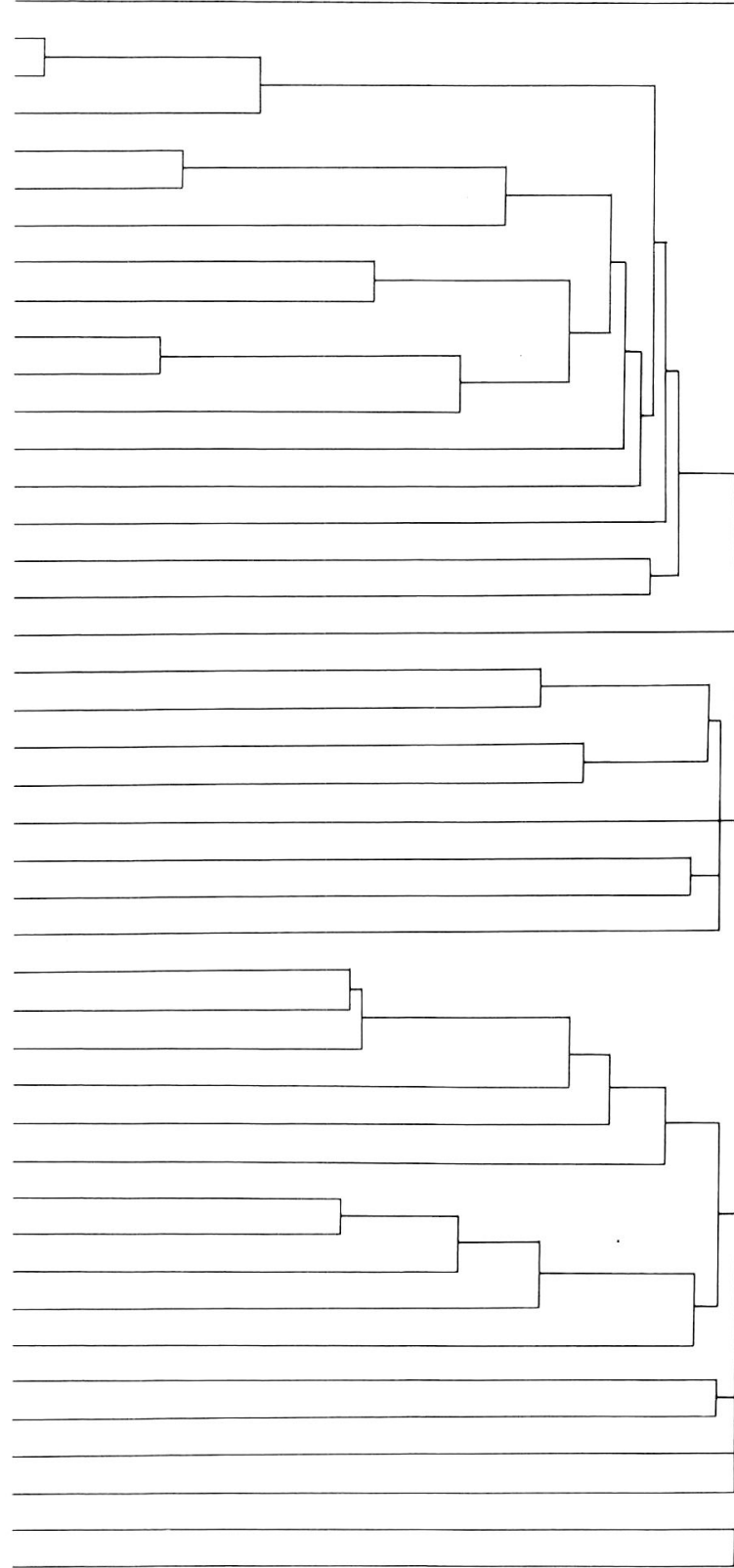

27. All other manf.

25. Transp. equipm.

45. Communications

23. Machinery

31. Retail gas stat's

42. Railroads

13. Apparel 
binding together the sectors in each cluster. The index (L) is the threshold associated with a particular cluster divided by 100 . Changes in $\mathrm{L}$ and in the composition of clusters indicate structural change.

One noticeable change that occurred among the 1965 clusters as compared to those for 1975 is the general decline in L. The decline in linkage strength between petroleum and natural gas (4) and gas companies and systems (47) is from 0.39 to 0.14 . Secondly, the cluster comprising chemicals (17) and instruments and related products (26) disappeared. The strength of the linkage for this group declined from 0.19 in 1965 to 0.05 in 1975. Another noteworthy change is that "all other" mining (5) is not in any of the 1965 clusters, but in 1975 it joined with general contractors-nonbuilding (17) and petroleum (18). Finally, the two coal mining sectors $(2,3)$ are members of the 1975 clusters, but not of the 1965 clusters.

\section{CONCLUSION}

The results indicate that significant structural change occurred in the West Virginia economy from 1965 to 1975 on both demand and supply sides. Noticeable changes on the demand side occurred in some manufacturing sectors. Significant changes occurred on the supply side in energy sectors. The next step is to determine the major causes of structural change in all sectors.

\section{FOOTNOTES}

1. Anthony L. Loviscek et. al. [9] and Miernyk et. al. [10].

2. Carter [4], p. 26.

3. Changing trade patterns also affect regional input coefficients. For more on this, see Beyers [2] and Conway [5].

4. In particular, the data for the 1965 tables were obtained by personal interview. The data for 1975, however, were obtained from a mail questionnaire supplemented by telephone interviews. This difference alone could lead to changes in coefficients.

5. Giarratani [6], p. 447. Others emphasizing the use of supply coefficients are Augustinovics [1] and Hoover [6], pp. 235-237.

6. For more on this, see Beyers [2].

7. The values for ${ }_{75} \mathrm{~W}_{\mathrm{i}}$ and ${ }_{75} \mathrm{Z}_{\mathrm{i}}$ are equal. The same is true for the values of ${ }_{75} \mathrm{~W}_{\mathrm{j}}$ and ${ }_{75} \mathrm{X}_{\mathrm{j}}$.
8. For more on this, see McGilvray [10].

9. Slater's method involves biproportionally standardizing transactions flows with diagonal entries removed. The algorithm then applies graph theory to the standardized flows.

10. This is an application of weak components of a directed graph. The existence of strong components, however, requires that a linkage not only exist from $\mathrm{i}$ to $\mathrm{j}$, but also from $\mathrm{j}$ to $\mathrm{i}$.

11. Visual observation shows that the threshold in Figure 1 differs from that of Figure 2. This is because a threshold is unique to its data base. As shown in Table 5, even if two dendrograms have identical clusters, the interindustry linkages of one cluster are likely to be different from that of the same cluster in the other dendrogram.

12. Slater [13], p. 3 .

\section{REFERENCES}

1. Augustinovics, M., (1970). "Methods of International and Intertemporal Comparison of Structure," in Contributions to Input-Output Analysis, eds. A. P. Carter and A. Brody, North Holland, Amsterdam.
2. Beyers, W. B., (1972). "On the Stability of Regional Interindustry Models: The Washington Data for 1963 and 1967," Journal of Regional Science, Vol. 12, pp. 363-374.

3. Campbell, J., (1972). "Selected Aspects of the 
Interindustry Structure of the State of Washington, 1967," Tijdschrift voor Economische en Sociale Geografie, Vol. 63, pp. 79-87.

4. Carter, A. P., (1970). Structural Change in the American Economy, Harvard University Press, Cambridge, MA.

5. Conway, R. S., (1976). "A Note on the Stability of Regional Interindustry Models," Journal of Regional Science, Vol. 15, pp. 67-72.

6. Giarratani, F., (1976). "Application of an Interindustry Supply Model to Energy Issues," Environment and Planning, Vol. 8 (1976), pp. 447-454.

7. Hoover, E., (1975). Regional Economics, 2nd ed., Alfred A. Knopf, New York.

8. Leontief, W., (1953). Studies in the Structure of the American Economy, Oxford University Press, New York.
9. Loviscek, A. L., et. al., (1979). The 1975 West Virginia Input-Output Study: Modeling a Regional Economy, West Virginia University Library, Morgantown.

10. McGilvray, J. W., (1977). "Linkages, Key Sectors, and Development Strategy," in Structure, System, and Economic Policy, ed. W. Leontief, Cambridge University Press, London.

11. Miernyk, W. H., et. al., (1970). Simulating Regional Economic Development, D. C. Heath, Lexington, MA.

12. Siebert, H., (1969). Regional Economic Growth: Theory and Policy, International Textbook, Scranton, PA.

13. Slater, P. B., (1977). "The Determination of Groups of Functionally Integrated Industries in the United States Using a 1967 Interindustry Flow Table," Empirical Economics, Vol. 2, pp. 1-9. 